\title{
Corrigendum: Transcriptome Analysis of Hamelia patens (Rubiaceae) Anthers Reveals Candidate Genes for Tapetum and Pollen Wall Development
}

\author{
Lin Yue ${ }^{1,2}$, David Twell ${ }^{3}$, Yanfeng Kuang ${ }^{1 *}$, Jingping Liao ${ }^{1}$ and Xianqiang Zhou ${ }^{4}$ \\ ${ }^{1}$ Key Laboratory of Plant Resources Conservation and Sustainable Utilization, South China Botanical Garden, Chinese \\ Academy of Sciences, Guangzhou, China, ${ }^{2}$ College of Life Sciences, University of Chinese Academy of Sciences, Beijing, \\ China, ${ }^{3}$ Department of Genetics, University of Leicester, Leicester, UK, ${ }^{4}$ Beijing Genomic Institute, Shenzhen, China
}

Keywords: transcriptome, Rubiaceae, Hamelia patens, anther, tapetum, pollen wall

\section{A corrigendum on}

\section{OPEN ACCESS}

Edited and reviewed by: Dazhong Dave Zhao, University of Wisconsin-Milwaukee,

${ }^{*}$ Correspondence: Yanfeng Kuang kuangyf05@scbg.ac.cn

Specialty section: This article was submitted to Plant Evolution and Development,

a section of the journal Frontiers in Plant Science

Received: 16 February 2017 Accepted: 01 March 2017 Published: 17 March 2017

Citation: Yue L, Twell D, Kuang Y, Liao J and Zhou X (2017) Corrigendum: Transcriptome Analysis of Hamelia patens (Rubiaceae) Anthers Reveals Candidate Genes for Tapetum and Pollen Wall Development.

Front. Plant Sci. 8:369. doi: 10.3389/fpls.2017.00369
Transcriptome Analysis of Hamelia patens (Rubiaceae) Anthers Reveals Candidate Genes for Tapetum and Pollen Wall Development

by Yue, L., Twell, D., Kuang, Y., Liao, J., and Zhou, X. (2017). Front. Plant Sci. 7:1991. doi: $10.3389 / \mathrm{fpls.2016.01991}$

There was a mistake in the order of "Figure 8," "Figure 9," and "Figure 10" as published. "Figure 8" should be modified to "Figure 9." "Figure 9" should be modified to "Figure 10." "Figure 10" should be modified to "Figure 8."

On page 13, the sentence "Real-time quantitative PCR (qRT-PCR) analysis was carried out on 20 candidate genes selected at random (Figure 9)" should be modified to "Real-time quantitative PCR (qRT-PCR) analysis was carried out on 20 candidate genes selected at random (Figure 10)."

On page 15, the sentence "In H. patens, BCP stage anthers were the most distinctive of the four stages, with the highest number of stage-specific and differentially expressed transcripts (Figure 10), showing great similarity to the TPA stage in rice (Deveshwar et al., 2011)" should be modified to "In $H$. patens, BCP stage anthers were the most distinctive of the four stages, with the highest number of stage-specific and differentially expressed transcripts (Figure 8), showing great similarity to the TPA stage in rice (Deveshwar et al., 2011)."

The authors apologize for the mistake. This error does not change the scientific conclusions of the article in any way.

Conflict of Interest Statement: The authors declare that the research was conducted in the absence of any commercial or financial relationships that could be construed as a potential conflict of interest.

Copyright (c) 2017 Yue, Twell, Kuang, Liao and Zhou. This is an open-access article distributed under the terms of the Creative Commons Attribution License (CC BY). The use, distribution or reproduction in other forums is permitted, provided the original author(s) or licensor are credited and that the original publication in this journal is cited, in accordance with accepted academic practice. No use, distribution or reproduction is permitted which does not comply with these terms. 